\title{
Folic Acid in Stroke Prevention in Countries without Mandatory Folic Acid Food Fortification: A Meta-Analysis of Randomized Controlled Trials
}

\author{
Chia-Yu Hsu, ${ }^{\mathrm{a}, *}$ Shao-Wen Chiu, ${ }^{\mathrm{a},{ }^{*}}$ Keun-Sik Hong, ${ }^{\mathrm{b}}$ Jeffrey L. Saver, ${ }^{\mathrm{c}}$ Yi-Ling Wu, ${ }^{\mathrm{d}}$ Jiann-Der Lee, ${ }^{\mathrm{a}}$ \\ Meng Lee, ${ }^{\mathrm{a}}$ Bruce Ovbiagele ${ }^{\mathrm{e}}$ \\ aDepartment of Neurology, Chang Gung Memorial Hospital, Chang Gung University College of Medicine, Chiayi, Taiwan \\ ${ }^{b}$ Department of Neurology, Inje University Ilsan Paik Hospital, Inje University College of Medicine, Goyang, Korea \\ 'Stroke Center and Department of Neurology, Geffen School of Medicine, University of California, Los Angeles, CA, USA \\ ${ }^{d}$ Research Services Center for Health Information, Chang Gung University, Taoyuan, Taiwan \\ 'Department of Neurosciences, Medical University of South Carolina, Charleston, SC, USA
}

Background and Purpose Additional folic acid (FA) treatment appears to have a neutral effect on reducing vascular risk in countries that mandate FA fortification of food (e.g., USA and Canada). However, it is uncertain whether FA therapy reduces stroke risk in countries without FA food fortification. The purpose of this study was to comprehensively evaluate the efficacy of FA therapy on stroke prevention in countries without FA food fortification.

Methods PubMed, EMBASE, and clinicaltrials.gov from January 1966 to August 2016 were searched to identify relevant studies. Relative risk (RR) with 95\% confidence interval (CI) was used as a measure of the association between FA supplementation and risk of stroke, after pooling data across trials in a random-effects model.

Results The search identified 13 randomized controlled trials (RCTs) involving treatment with FA that had enrolled 65,812 participants, all of which stroke was reported as an outcome measure. After all 13 RCTs were pooled, FA therapy versus control was associated with a lower risk of any future stroke ( $R R, 0.85 ; 95 \% \mathrm{Cl}, 0.77$ to 0.95). FA alone or combination of FA and minimal cyanocobalamin ( $\leq 0.05 \mathrm{mg} /$ day) was associated with a lower risk of future stroke (RR, 0.75; 95\% $\mathrm{Cl}, 0.66$ to 0.86 ) whereas combination of FA and cyanocobalamin ( $\geq 0.4 \mathrm{mg} /$ day) was not associated with a lower risk of future stroke $(\mathrm{RR}, 0.95 ; 95 \% \mathrm{Cl}, 0.86$ to 1.05$)$.

Conclusions FA supplement reduced stroke in countries without mandatory FA food fortification. The benefit was found mostly in patients receiving FA alone or combination of FA and minimal cyanocobalamin.

Keywords Folic acid; Stroke; Prevention; Food, fortified; Meta-analysis
Correspondence: Meng Lee Department of Neurology, Chang Gung Memorial Hospital, Chang Gung University College of Medicine, 6 , West Section, Chiapu Road, Puzi City, Chiayi County 613, Taiwan Tel: +886-5-3621000

Fax: +886-5-3623002

E-mail:menglee5126@gmail.com

Received: July 10, 2017

Revised: September 11, 2017

Accepted: September 18, 2017

*These authors contributed equally to the manuscript as first author.

\section{Introduction}

Homocysteine, a sulfur-containing amino acid, was thought to be an independent vascular risk factor. ${ }^{1}$ Hyperhomocysteinemia was related with endothelium dysfunction and procoagulation state through mechanisms of altering vascular morphology, stimulating inflammation, activating the endothelium and the blood clotting cascade, and inhibiting fibrinolysis. ${ }^{2}$ A 25\% low- 
er usual total homocysteine level was associated with a 19\% lower stroke risk. ' Folic acid, as a cofactor of enzymes involved in homocysteine metabolism, could lower total homocysteine by $20 \%$ to $25 \%{ }_{1}^{3}$ and it was supposed to decrease the risk of vascular events. Many randomized controlled trials (RCTs) had been conducted to evaluate the efficacy of folic acid supplementation for the prevention of cardiovascular/cerebrovascular diseases, but their results were diverging.

To our knowledge, meta-analyses regarding this issue mostly found no benefit of folic acid for coronary artery disease prevention. ${ }^{4,5}$ However, there might be slight benefits in terms of stroke prevention..$^{5-8} \mathrm{~A}$ meta-analysis found folic acid supplementation reduced the stroke risk by $11 \%$ in the 10 trials with no or partial folic acid fortification but had no benefit on stroke risk in the other five trials with folic acid mandatory fortification. Indeed, a population-based cohort study had found stroke mortality decreased in United States and Canada after mandatory folic acid fortification. ${ }^{9}$ Therefore, additional folic acid supplementation in these countries may have limited benefit to further reduce stroke risk. On the other hand, in the countries without mandatory folic acid fortification, weather folic acid supplementation could prevent stroke would be an important issue for public health.

Some RCTs carried out in the countries without folic acid fortification have been published in the interval since the most recent meta-analysis and offered more evidence on this issue. ${ }^{10,11}$ Therefore, we undertook an update meta-analysis to evaluate the efficacy of folic acid therapy on stroke prevention in countries without mandatory folic acid food fortification.

\section{Methods}

This study was performed in accordance with the recommendations of the preferred reporting items for systematic reviews and meta-analysis: the PRISMA statement. ${ }^{12}$

\section{Search strategy}

We searched PubMed, EMBASE, and the clinical trial registry maintained at clinicaltrials.gov from January 1966 to September 2016 using the search strategy "homocysteine" or "folate" or "folic acid" or "vitamin B12" or "cobalamin" or "vitamin B6" or "pyridoxine" or "multivitamin" and "cardiovascular disease" or "myocardial infarct" or "myocardial ischemia" or "coronary heart disease" or "angina" or "heart attack" or "stroke" or "cerebrovascular disease" or "cerebrovascular attack" or "brain attack" or "brain infarct" or "brain hemorrhage" or "intracranial hemorrhage." We restricted our search to human beings and clinical trials. There were no language restrictions. We also re- viewed the introduction and discussion sections of retrieved trials and of prior meta-analyses to identify additional trials.

Included criteria for studies were as follows: (1) the study designed as an RCT; (2) the active treatment comprised folic acid supplementation (with or without additional vitamin B supplementation); (3) total participants and number of stroke events were reported as an outcome endpoint; (4) duration of active treatment at least 6 months; and (5) most participants $(>50 \%)$ in a trial resided in countries without mandatory folic acid food fortification. Participants of any age or sex were included.

Since mandatory folic acid supplement has been applied to United States (since 1998), Canada (since 1998), Costa Rica (since 1998), Chile (since 2000), and South Africa (since 2003), trials with $>50 \%$ of participants resided in these countries were excluded.

All data from eligible trials were abstracted in duplicate by two investigators independently (C.Y.H. and Y.L.W.) with a standard protocol. Discrepancies were resolved by discussion with a third investigator (M.L.) and by referencing the original report.

\section{Study quality assessment}

Since all the included studies were RTCs, the risk of bias (e.g., selection bias, performance bias, detection bias, attrition bias, and reporting bias) of the included trials was assessed by $\mathrm{Co}_{0}$ chrane risk-of bias algorithm (www.cohchrane.org/training/cochrane-handbook). ${ }^{13}$

\section{Primary and secondary endpoints}

The primary endpoint was stroke (ischemic or hemorrhagic). The secondary endpoints were ischemic stroke and hemorrhagic stroke, respectively. Subgroup analyses were conducted according to different study characteristics: treatment duration ( $<3$ years vs. $\geq 3$ years), sample size $(<1,000$ vs. $\geq 1,000)$, and mean age at entry ( $<65$ years vs. $\geq 65$ years).

\section{Statistical analysis}

All analyses were based on the intention-to-treat principle. Relative risk (RR) with 95\% confidence interval $(\mathrm{Cl})$ was used as a measure of the association between folic acid supplementation and risk of stroke. We report absolute risks in terms of the difference in the number of events per 1,000 patients and the respective $95 \% \mathrm{Cl}$. We computed a random-effects estimate based on the Mantel-Haenszel method when two or more studies provided sufficient data for a given outcome and compared the results with those obtained from a fixed-effects model. Statistical heterogeneity was assessed by the chi-square and the $\mathrm{I}^{2}$ statistics. Heterogeneity was considered if either the chi-square test was 
significant with the $P=0.10$ level, or the $I^{2}$ statistic was greater than $50 \%$. Publication bias was estimated visually by funnel plots displaying standard error as the measure of sample size and RR as the measure of treatment effect. ${ }^{14}$ We also performed a sensitivity analysis to further explore the robustness of our results. To identify any study that might have exerted a disproportionate influence on the summary treatment effect, we removed each individual trial from the meta-analysis one at a time. Subgroup analyses were conducted based on the baseline characteristics. This meta-analysis was analyzed by Cochrane Collaboration's Review Manager Software Package (RevMan version 5.3, The Cochrane Collaboration, London, UK).

To evaluate whether the present meta-analysis had sufficient sample size to reach firm conclusions about the effect of interventions, trial sequential analysis was performed for the primary endopint. ${ }^{15}$ Trial sequential analysis performs accumulative meta-analysis, which creates $Z$ curve of the summarized observed effect and the monitoring boundaries for benefit, harm, and futility, and it estimates the required information size. These boundaries and analyses are adjusted to account for the amount of available evidence and to control for repeated analyses, while maintaining type I error at 5\% and the power at $80 \%$. The required information size was calculated based on event rates observed in control group and folic acid group. If the $Z$ curve of the cumulative meta-analysis crosses one of the boundaries, no further studies are required, and there is sufficient evidence to support the conclusions.

\section{Results}

The literature review identified 54 articles for detailed assessment, among which 32 were excluded for not reporting stroke as an endpoint, nine were excluded for being conducted in countries with mandatory folic acid fortification, ${ }_{1}^{16-24}$ and our final analysis included 13 RCTs, conducted in countries without mandatory folic acid fortification, involving treatment with folic acid (Figure 1)..$^{10,11,25-35}$ Included ${ }^{10,11,25-35}$ versus excluded trials $^{16-24}$ based on whether they were conducted mostly in countries without mandatory folic acid fortification were presented in Table 1. Study design characteristics and baseline characteristics of included trials were presented in Table $2 .^{10,11,25-35}$ Overall, 65,812 participants were enrolled with 33,741 (51\%) participants randomly assigned to the folic acid therapy group and 32,071 (49\%) to the control group. Among 13 trials, 12 trials included individuals with preexisting conditions: stroke (one trial), coronary heart disease (five trials), ${ }_{1}^{26-28,31,35}$ cardiovascular disease (one trial), ${ }_{1}^{32}$ end-stage renal disease or advanced chronic kidney disease (three trials), ${ }_{1}^{29,30,34}$ hypertension (one trial), ${ }^{10}$ and

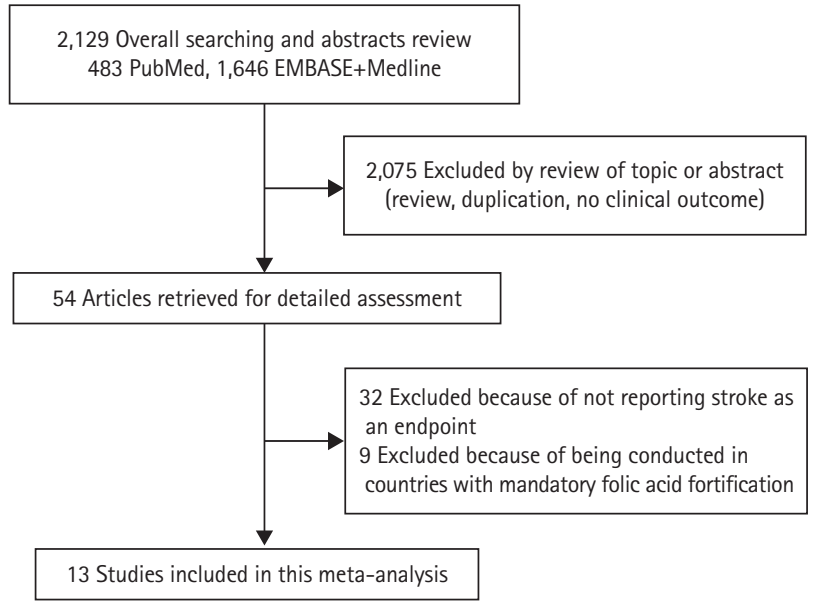

Figure 1. Flow chart of study selection.

esophageal dysplasia (one trial) ${ }^{25}$ while one trial included individuals living in high altitude." Folic acid alone or combination of folic acid and minimal cyanocobalamin ( $\leq 0.05 \mathrm{mg} /$ day) was used in an active treatment group in eight trials $10,25-27,29,30,32,34$ whereas combination of folic acid and cyanocobalamin $(\geq 0.4$ $\mathrm{mg} /$ day) was used in an active treatment group in five trials. ${ }^{11,28,31,33,35}$ Three trials excluded participants with chronic kidney disease $\mathrm{e}^{26,27,32}$ while other trials included some participants with chronic kidney disease. Cerebrovascular events analyzed were combined nonfatal and fatal strokes (ischemic and hemorrhagic) in 10 trials; for one trial each, data were available only on fatal stroke; ${ }^{25}$ non-fatal and fatal ischemic stroke; $; 1$ and the composite of nonfatal and fatal stroke plus transient ischemic attack. ${ }^{27}$ Neuroimaging was explicitly mentioned as part of the stroke event ascertainment process in seven trials. . $^{1011,28,29,31,34}$

Risk-of-bias assessment of included trials was reported in Supplementary Table 1. The results from Liem et al. ${ }^{26}$, Liem et al. ${ }^{27}$, and Righetti et al. ${ }^{29}$ had high risks of performance bias and detection bias because these were an open, non-blinded studies.

After all 13 trials were pooled, folic acid therapy versus control was associated with a lower risk of any future stroke $(R R, 0.85$; $95 \% \mathrm{Cl}, 0.77$ to $0.95 ; P=0.004 ; 3$ to 8 fewer events $/ 1,000$ patients). Folic acid alone or combination of folic acid and minimal cyanocobalamin ( $\leq 0.05 \mathrm{mg} /$ day) was associated with a lower risk of future stroke $(\mathrm{RR}, 0.75 ; 95 \% \mathrm{Cl}, 0.66$ to $0.86 ; P<0.0001)$ whereas combination of folic acid and cyanocobalamin ( $\geq 0.4 \mathrm{mg} /$ day) was not associated with a lower risk of future stroke ( $R R, 0.95$; $95 \% \mathrm{Cl}, 0.86$ to $1.05 ; P=0.30$ ) (Figure 2). There was slightly asymmetrical appearance on the funnel plot suggesting a small degree of publication bias, with a slight under-representation of studies showing neutral effects (Supplementary Figure 1). Sensitivity analyses excluding individual trials yielded pooled results that were not 
Table 1. Included versus excluded trials based on whether they were conducted mostly in countries without mandatory folic acid fortification

\begin{tabular}{|c|c|c|c|c|}
\hline Study & Preexisting condition & Control & Study period & $\begin{array}{l}\text { Participants from the coun- } \\
\text { tries without mandatory FA } \\
\text { fortification* }\end{array}$ \\
\hline \multicolumn{5}{|l|}{ Included studies } \\
\hline Mark et al. $(1996)^{25}$ & Esophageal dysplasia & Placebo & 1985-1991 & 100\% (China) \\
\hline Liem et al. $(2004)^{26}$ & $\begin{array}{l}\text { Acute MI with } \\
\text { hyperlipidemia }\end{array}$ & Usual care & 1998-2003 & $100 \%$ (Netherland) \\
\hline Liem et al. $(2005)^{27}$ & $\begin{array}{l}\text { CHD with } \\
\text { hyperlipidemia }\end{array}$ & Usual care & 1998-2003 & 100\% (Netherland) \\
\hline ASFAST $(2006)^{30}$ & $\begin{array}{l}\text { Creatinine clearance } \\
<25 \mathrm{~mL} / \mathrm{min}\end{array}$ & Placebo & $\begin{array}{l}\text { June 1998- } \\
\text { December } 2003\end{array}$ & $\begin{array}{l}100 \% \\
\text { (Australia and New Zealand) }\end{array}$ \\
\hline NORVIT $(2006)^{28}$ & Acute MI & Placebo & $\begin{array}{l}\text { December 1998- } \\
\text { March } 2002\end{array}$ & $100 \%$ (Norway) \\
\hline $\begin{array}{l}\text { Righetti et al. } \\
(2006)^{29}\end{array}$ & $\begin{array}{l}\text { ESRD under } \\
\text { hemodialysis }\end{array}$ & Usual care & $\begin{array}{l}\text { January 2001- } \\
\text { December } 2005\end{array}$ & 100\% (Italy) \\
\hline WENBIT $(2008)^{31}$ & $\begin{array}{l}\mathrm{CHD} \text { and/or aortic } \\
\text { valve stenosis }\end{array}$ & Placebo & $\begin{array}{l}\text { January 2000- } \\
\text { April } 2004\end{array}$ & 100\% (Norway) \\
\hline Heinz et al. $(2010)^{34}$ & $\begin{array}{l}\text { ESRD under } \\
\text { hemodialysis }\end{array}$ & Low dose vitamin $B$ & July 2002-July 2008 & 100\% (Germany) \\
\hline SEARCH $(2010)^{35}$ & Ml & Placebo & 1998-2008 & $100 \%$ (UK) \\
\hline SU.FOL.OM3 $(2010)^{32}$ & CVD & Placebo & February 2003- June 2007 & 100\% (France) \\
\hline VITATOPS (2010) ${ }^{33}$ & Stroke or TIA & Placebo & $\begin{array}{l}\text { November 1998- } \\
\text { December } 2008\end{array}$ & $\begin{array}{l}\text { 99.3\% } \\
\text { (Australia, Austria, Brazil, Bel- } \\
\text { gium, China, India, Italy, Mol- } \\
\text { dova, Malaysia, Netherland, } \\
\text { New Zealand, UK, Pakistan, } \\
\text { Philippines, Protugal, Georgia, } \\
\text { Sorbia, Singapore, Sri Lanka) }\end{array}$ \\
\hline CSPPT $(2015)^{10}$ & Hypertension & Usual care & May 2008- August 2013 & 100\% (China) \\
\hline Kotwal et al. (2015) ${ }^{11}$ & High-altitude & Usual care & May 2006- August 2006 & 100\% (India) \\
\hline
\end{tabular}

Excluded studies due to more than $50 \%$ participants from countries with mandatory FA fortification

\begin{tabular}{|c|c|c|c|c|c|}
\hline VISP $(2004)^{16}$ & Ischemic stroke & Low dose vitamin $B$ & $\begin{array}{l}\text { September 1996- } \\
\text { May } 2003\end{array}$ & 1 Center in Scotland & $\begin{array}{l}45 \text { Centers in USA and } \\
10 \text { Centers in Canada }\end{array}$ \\
\hline Wrone et al. (2004) $)^{17}$ & ESRD & Low dose vitamin $B$ & March 1998- May 1999 & - & $100 \%$ (USA) \\
\hline HOPE-2 (2006) $)^{18}$ & $\begin{array}{l}\text { Vascular disease or } \\
\text { diabetes }\end{array}$ & Placebo & $2000-2005$ & $\begin{array}{l}\text { 27.9\% (Western Europe, } \\
\text { Brazil, Slovakia) }\end{array}$ & $\begin{array}{l}72.1 \% \\
\text { (USA and Canada) }\end{array}$ \\
\hline $\begin{array}{l}\text { Jamison et al. } \\
(2007)^{20}\end{array}$ & $\begin{array}{l}\text { Advanced CKD and } \\
\text { ESRD }\end{array}$ & Placebo & $\begin{array}{l}\text { September 2001- } \\
\text { May } 2006\end{array}$ & - & $100 \%$ (USA) \\
\hline Cole et al. $(2007)^{19}$ & Colorectal adenoma & Placebo & July 1994- October 2004 & - & $100 \%$ (USA) \\
\hline Albert $(2008)^{21}$ & CVD & Placebo & April 1998-July 2005 & - & $100 \%$ (USA) \\
\hline $\begin{array}{l}\text { House et al. } \\
(2010)^{22}\end{array}$ & Diabetic nephropathy & Placebo & May 2001-July 2007 & - & 100\% (Canada) \\
\hline $\begin{array}{l}\text { Bostom et al. } \\
(2011)^{23}\end{array}$ & Kidney transplant & Low dose vitamin B & $\begin{array}{l}\text { August 2002- } \\
\text { January } 2010\end{array}$ & 14.9\% (Brazil) & $\begin{array}{l}85.1 \% \\
\text { (Canada and USA) }\end{array}$ \\
\hline Lamas et al. $(2013)^{24}$ & Myocardial infarction & Placebo & $\begin{array}{l}\text { September 2003- } \\
\text { October } 2011\end{array}$ & - & $\begin{array}{l}100 \% \\
\text { (USA and Canada) }\end{array}$ \\
\hline
\end{tabular}

FA, folic acid; MI, myocardial infarction; CHD, coronary heart disease; ASFAST, Atherosclerosis and Folic Acid Supplementation Trial; NORVIT, Norwegian Vitamin; ESRD, end-stage renal disease; WENBIT, Western Norway B-Vitamin Intervention Trial; SEARCH, Study of the Effectiveness of Additional Reductions in Cholesterol and Homocysteine; SU.FOL.OM3, SUpplementation with FOlate, vitamin B6 and B12 and/or OMega-3 fatty acids; CVD, cardiovascular disease; VITATOPS, VITAmins TO Prevent Stroke; TIA, transient ischemic attack; CSPPT, China Stroke Primary Prevention Trial; VISP, Vitamin Intervention for Stroke Prevention; HOPE-2, Heart Outcomes Prevention Evaluation 2; CKD, chronic kidney disease.

${ }^{*}$ Countries with mandatory folic acid supplement included USA (since 1998), Canada (since 1998), Costa Rica (since 1998), Chile (since 2000), and South Africa (since 2003). 


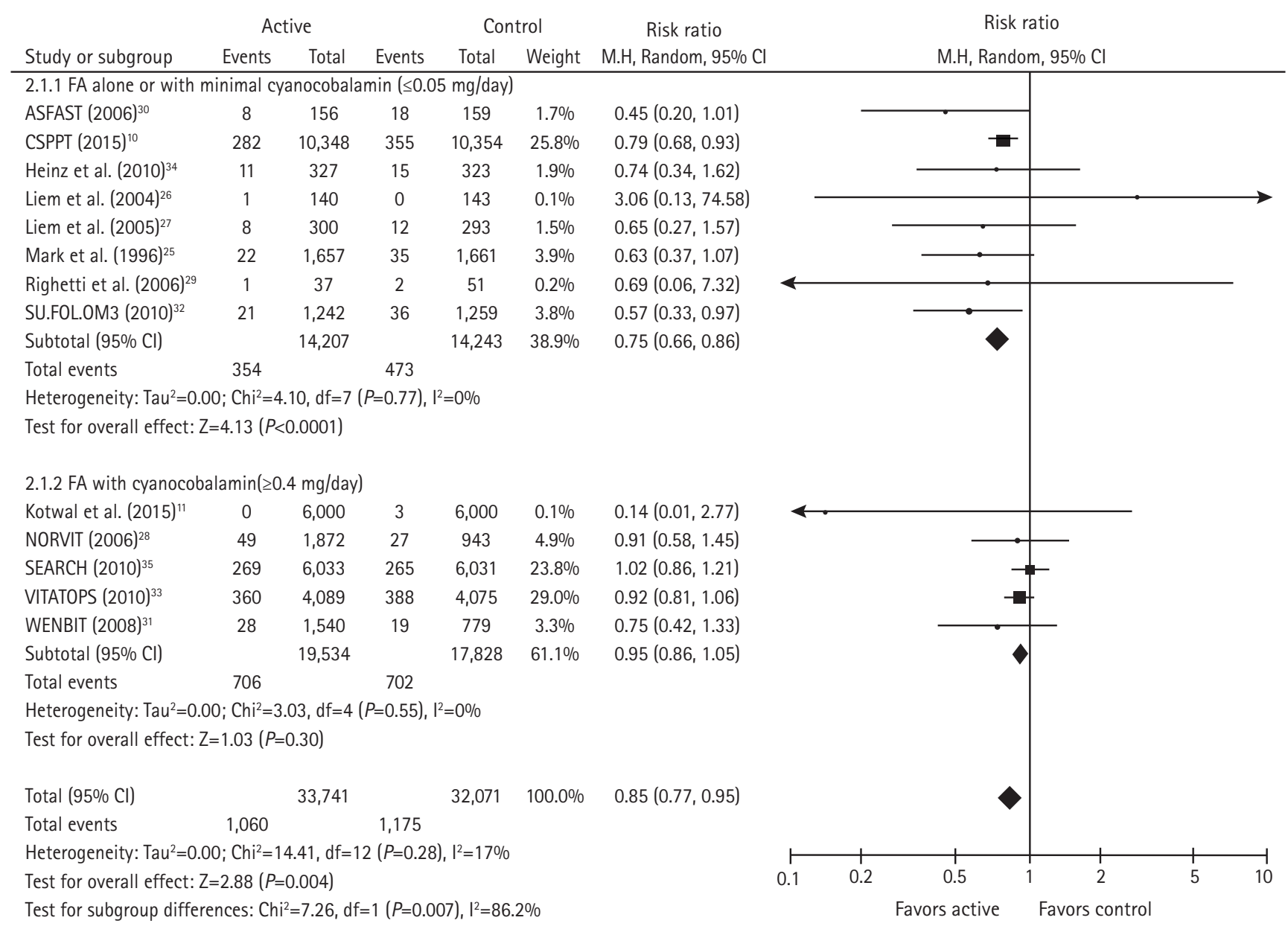

Figure 2. Risk ratio with $95 \% \mathrm{Cl}$ estimates for stroke (active treatment vs. control), by trial and pooled. $\mathrm{M}-\mathrm{H}$, Mantel-Haenszel methods; $\mathrm{Cl}$, confidence interval; FA, folic acid; ASFAST, Atherosclerosis and Folic Acid Supplementation Trial; CSPPT, China Stroke Primary Prevention Trial; SU.FOL.OM3, SUpplementation with FOlate, vitamin B6 and B12 and/or OMega-3 fatty acids; NORVIT, Norwegian Vitamin; SEARCH, Study of the Effectiveness of Additional Reductions in Cholesterol and Homocysteine; VITATOPS, VITAmins TO Prevent Stroke; WENBIT, Western Norway B-Vitamin Intervention Trial.

significantly different from the overall pooled estimates (Table 3). Trial sequential analysis was conducted and showed the number of patients evaluated $(n=65,812)$ almost reached the required information sizes $(n=66,784)$ and the summarized observed effect crossed benefit boundary (Figure 3).

Two trials reported data on ischemic stroke and one trial reported data on hemorrhagic stroke. There was no evidence of an effect of folic acid on ischemic (RR, $0.65 ; 95 \% \mathrm{Cl}, 0.25$ to $1.71 ; P=0.38)$ and hemorrhagic stroke $(\mathrm{RR}, 0.94 ; 95 \% \mathrm{Cl}, 0.66$ to $1.34 ; P=0.72)$, respectively. The overall qualities of evidence were high in stroke endpoint and low in ischemic stroke (Supplementary Table 2).

In subgroup analyses, folic acid therapy was associated with a reduction or decreasing trend in the risk of subsequent strokes when we stratified the estimates by treatment duration, sample size, and mean age at entry. There was also no obvious heterogeneity among the different study characteristics (Figure 4).

\section{Discussion}

In this meta-analysis of 13 RCTs of generally good quality, among over 65,000 people living in countries without mandatory folic acid fortification in food, we found that addition of folic acid was associated with a 15\% RR reduction in future stroke risk. Folic acid alone or combination of folic acid and minimal cyanocobalamin ( $\leq 0.05 \mathrm{mg} /$ day) was associated with a 25\% lower risks of future stroke whereas combination of folic acid and cyanocobalamin ( $\geq 0.4 \mathrm{mg} /$ day) was not associated with lower risks of future stroke. While five fewer stroke events $/ 1,000$ patients may seem modest, additional folic acid supplementation may be associated with huge benefits with inexpensive cost, since most countries have not adopted mandatory folic acid fortification. This updated meta-analysis provided robust evidence of beneficial effects of folic acid supplementation for stroke prevention in countries that do not have 
Table 2. Characteristics of included trials

\begin{tabular}{|c|c|c|c|c|c|c|c|c|c|}
\hline Study & $\begin{array}{l}\text { Sample } \\
\text { size }\end{array}$ & $\begin{array}{l}\text { Age } \\
\text { (yr) }\end{array}$ & $\begin{array}{l}\text { Men } \\
(\%)\end{array}$ & $\begin{array}{c}\text { FA daily dose in } \\
\text { treatment arm } \\
(\mathrm{mg})\end{array}$ & $\begin{array}{l}\text { Vitamin B12 } \\
\text { daily dose } \\
\text { in treatment } \\
\text { arm }(\mathrm{mg})\end{array}$ & $\begin{array}{l}\text { Duration } \\
\text { (mo) }\end{array}$ & $\begin{array}{l}\text { Stroke } \\
\text { definition }\end{array}$ & CKD & $\begin{array}{l}\text { Prior } \\
\text { stroke }\end{array}$ \\
\hline Mark et al. $(1996)^{25}$ & 3,318 & 54 & 44 & 0.8 & 0.018 & 72 & Fatal stroke & NR & NR \\
\hline Liem et al. $(2004)^{26}$ & 283 & 59 & 70 & 5 & 0 & 12 & Fatal and nonfatal stroke & $0 \%$ & NR \\
\hline Liem et al. $(2005)^{27}$ & 593 & $65.2 \pm 9.8$ & 78 & 0.5 & 0 & 42 & $\begin{array}{l}\text { Fatal and nonfatal stroke } \\
\text { and TIA }\end{array}$ & $0 \%$ & $7 \%$ \\
\hline ASFAST $(2006)^{30}$ & 315 & $56 \pm 13$ & 68 & 15 & 0 & 43 & Fatal and nonfatal stroke & 100\% (ESRD) & $9 \%$ \\
\hline NORVIT $(2006)^{28}$ & $2,815^{*}$ & $63.2 \pm 11.6$ & 74 & 0.8 & 0.4 & 36 & Fatal and nonfatal stroke & $23.8 \%(\mathrm{Cr}>1.13 \mathrm{mg} / \mathrm{dL})$ & $4 \%$ \\
\hline $\begin{array}{l}\text { Righetti et al. } \\
(2006)^{29}\end{array}$ & 88 & $64.5 \pm 1.8$ & 56 & 5 & $\begin{array}{l}\text { Not added in } \\
\text { most patients }\end{array}$ & 29 & Fatal and nonfatal stroke & $100 \%$ (ESRD) & NR \\
\hline WENBIT $(2008)^{31}$ & $2,319^{*}$ & $61.7 \pm 10.1$ & 79 & 0.8 & 0.4 & 38 & Fatal and nonfatal stroke & $11.9 \%$ (eGFR $<60 \mathrm{~mL} / \mathrm{min})$ & $6 \%$ \\
\hline Heinz et al. $(2010)^{34}$ & 650 & $61 \pm 13$ & 58 & 5 & 0.05 & 25 & Fatal and nonfatal stroke & 100\% (ESRD) & NR \\
\hline SEARCH $(2010)^{35}$ & 12,064 & $64.2 \pm 8.9$ & 83 & 2 & 1 & 78 & Fatal and nonfatal stroke & $14 \%(\mathrm{eGFR}<60 \mathrm{~mL} / \mathrm{min})$ & $7 \%$ \\
\hline VITATOPS $(2010)^{33}$ & 8,164 & $62.6 \pm 12.5$ & 64 & 2 & 0.5 & 41 & Fatal and nonfatal stroke & $11 \%(\mathrm{Cr}>1.36 \mathrm{mg} / \mathrm{dL})$ & $100 \%$ \\
\hline SU.FOL.OM3 $(2010)^{32}$ & 2,501 & $61 \pm 9$ & 79 & 0.56 & 0.02 & 56 & Fatal and nonfatal stroke & $0 \%$ & $26 \%$ \\
\hline CSPPT $(2015)^{10}$ & 20,702 & $60 \pm 7.5$ & 41 & 0.8 & 0 & 60 & Fatal and nonfatal stroke & $10.9 \%$ & $0 \%$ \\
\hline Kotwal et al. (2015) & 12,000 & $N R$ & NR & 5 & 1 & 24 & Ischemic stroke & NR & NR \\
\hline
\end{tabular}

FA, folic acid; CKD, chronic kidney disease; NR, not reported; TIA, transient ischemic attack; ASFAST, Atherosclerosis and Folic Acid Supplementation Trial; ESRD, end-stage renal disease; NORVIT, Norwegian Vitamin; WENBIT, Western Norway B-Vitamin Intervention Trial; eGFR, estimated glomerular filtration rate; SEARCH, Study of the Effectiveness of Additional Reductions in Cholesterol and Homocysteine; VITATOPS, VITAmins TO Prevent Stroke; SU.FOL.OM3, SUpplementation with FOlate, vitamin B6 and B12 and/or OMega-3 fatty acids; CSPPT, China Stroke Primary Prevention Trial.

${ }^{*}$ Combined 2 factors with FA vs. placebo control: 1 factor with vitamin B6 only was not included.

Table 3. Sensitivity analyses to remove each individual trial from the metaanalysis 1 at a time

\begin{tabular}{lc}
\hline & Relative risk (95\% confidence interval) \\
\hline All 13 trials included & $0.85(0.77-0.95)$ \\
Removed & \\
ASFAST (2006) & $0.87(0.80-0.96)$ \\
CSPPT (2015) ${ }^{10}$ & $0.88(0.77-0.99)$ \\
Heinz et al. $(2010)^{34}$ & $0.85(0.76-0.96)$ \\
Kotwal et al. $(2015)^{11}$ & $0.86(0.77-0.95)$ \\
Liem et al. $(2004)^{26}$ & $0.85(0.76-0.95)$ \\
Liem et al. $(2005)^{27}$ & $0.85(0.76-0.96)$ \\
Mark et al. $(1996)^{25}$ & $0.87(0.78-0.96)$ \\
NORVIT (2006) $)^{28}$ & $0.84(0.75-0.95)$ \\
Righetti et al. $(2006)^{29}$ & $0.85(0.75-0.95)$ \\
SEARCH (2010) & $0.83(0.76-0.91)$ \\
SU.FOL.OM3 (2010) & $0.87(0.79-0.96)$ \\
VITATOPS $(2010)^{33}$ & $0.82(0.71-0.94)$ \\
WENBIT $(2008)^{31}$ & $0.85(0.76-0.96)$
\end{tabular}

ASFAST, Atherosclerosis and Folic Acid Supplementation Trial; CSPPT, China Stroke Primary Prevention Trial; NORVIT, Norwegian Vitamin; SEARCH, Study of the Effectiveness of Additional Reductions in Cholesterol and Homocysteine; SU.FOL.OM3, SUpplementation with FOlate, vitamin B6 and B12 and/or OMega-3 fatty acids; VITATOPS, VITAmins TO Prevent Stroke; WENBIT, Western Norway B-Vitamin Intervention Trial. mandatory folic acid fortification in food.

The finding of no benefits in trials with patients receiving folic acid plus cyanocobalamin ( $\geq 0.4 \mathrm{mg} /$ day) deserved further exploration. ${ }^{11,30,31,33,35}$ All these trials included some participants with chronic kidney disease. ${ }^{1128,31,33,35}$ In the DIVINe trial, ${ }^{22}$ in patients with diabetic nephropathy, B vitamins including cyanocobalamin $1,000 \mathrm{mcg}$ daily were harmful, accelerating the decline of renal function, and doubling cardiovascular events. All the events occurred among participants with estimated glomerular filtration rate $<50 \mathrm{~mL} / \mathrm{min} / 1.73$ $\mathrm{m}^{2}{ }^{36}$ In the Vitamin Intervention for Stroke Prevention (VISP) subgroup analysi ${ }^{37}$ that excluded participants with estimated glomerular filtration rate $<48 \mathrm{~mL} / \mathrm{min} / 1.73 \mathrm{~m}^{2}$ (the lowest $10 \%)$, there was a significant benefit of B vitamins including cyanocobalamin. It now appears that the reason the early studies that did not show a reduction of stroke (e.g., VISP, Norwegian Vitamin [NORVIT]) was because high cyanide levels in patients with renal failure resulted in toxicity of cyanocobalamin. ${ }^{38,39}$ On the other hand, the benefit of folic acid monotherapy was found in the huge Chinese trial (China Stroke Primary Prevention Trial [CSPPT)], even among participants with impaired renal function. ${ }^{40}$ Furthermore, in countries with folate fortification the main nutritional cause of high total homocysteine is metabolic B12 deficiency, which is 


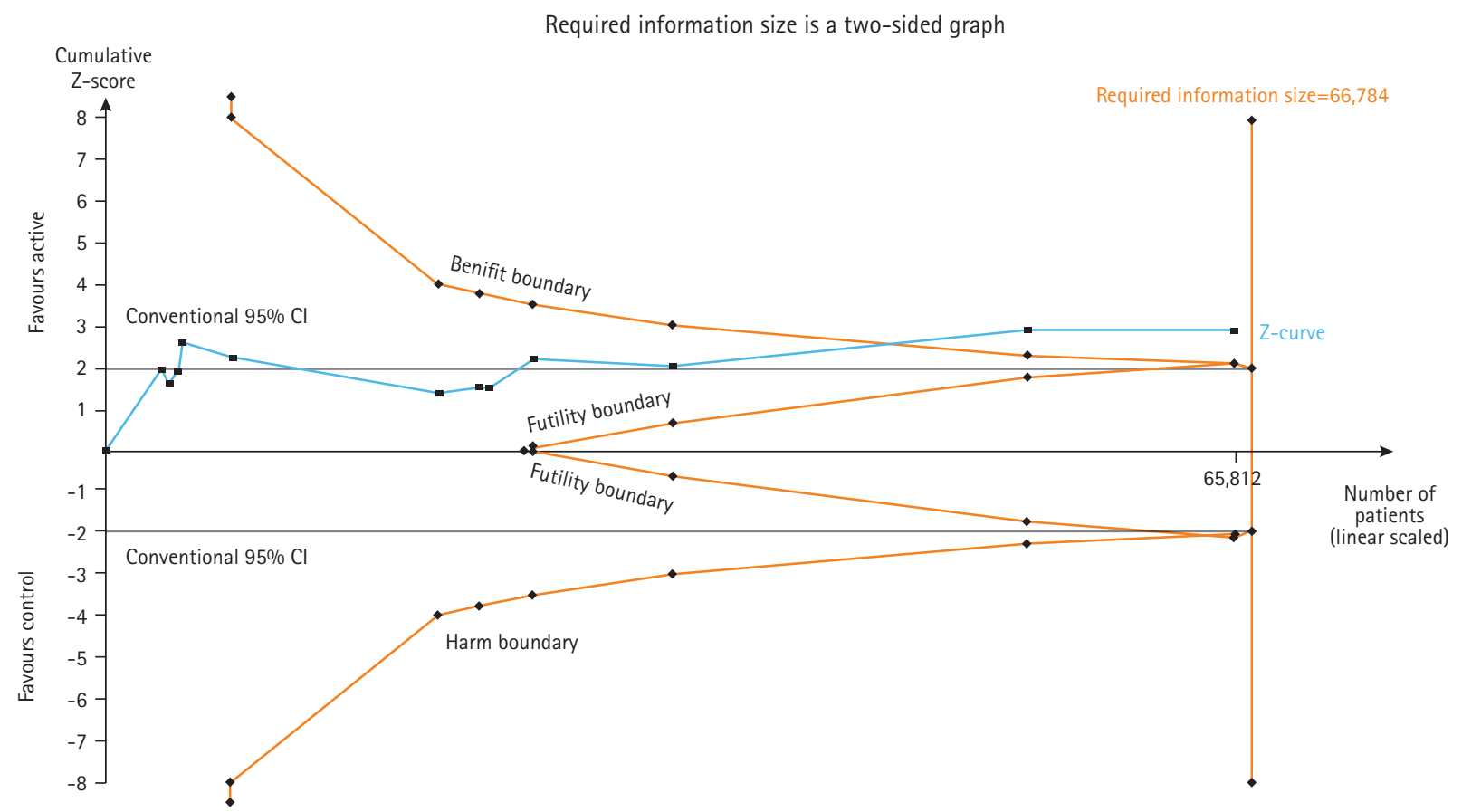

Figure 3. Trial sequential analysis of 13 trials comparing folic acid and control for stroke in countries without mandatory folic acid fortification. A cumulative Z-curve almost reached the required information size boundary and has crossed benefit boundary. $\mathrm{Cl}$, confidence interval.

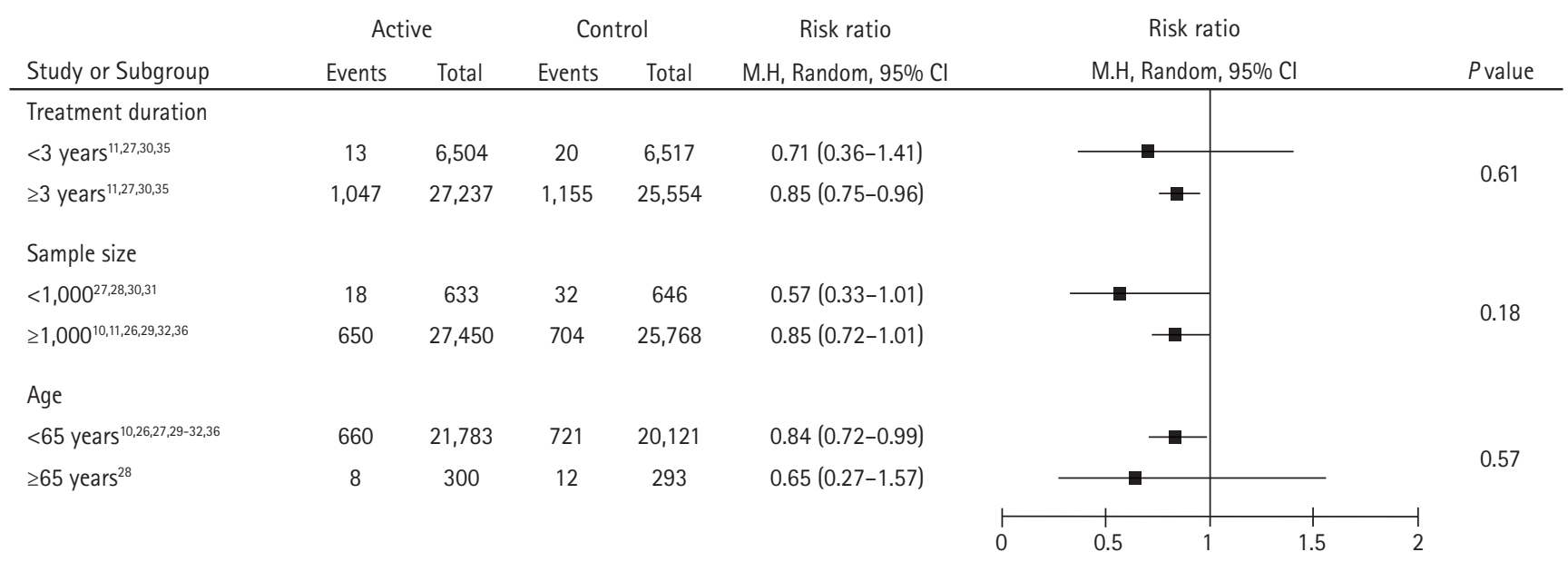

Figure 4. Effect of folic acid supplementation on the risk of stroke in prespecified subgroups. $\mathrm{M}-\mathrm{H}$, Mantel-Haenszel methods; $\mathrm{Cl}$, confidence interval.

very common (30\% of stroke patients over age 70 ) and often missed. ${ }^{41}$ The reason it is missed is that a normal serum total B12 does not confirm adequate levels of active cobalamin; to do so requires measuring holotranscobalamin, methylmalonic acid or total homocysteine. ${ }^{42}$ It has been suggested that metabolic B12 deficiency should be investigated and treated in all stroke patients. Methylcobalamin or hydroxocobalamin should be used, particularly in patients with renal impairment. $^{38}$
The different effect of folic acid on myocardial infarction and stroke is worthy of comment. Myocardial infarction is mostly due to plaque rupture in the coronary artery and its mechanism is large vessel atherosclerosis. The mechanisms of stroke are more heterogeneous, including cardioembolism, large vessel atherosclerosis and small vessel disease. Within the stroke subtypes, small vessel disease was found to have strongest association with total homocysteine in many populations. ${ }^{43-46}$ Total homocysteine was also related to silent brain infarct and 
white matter lesions on magnetic resonance imaging of brain. ${ }^{47-50}$ Beyond cerebral small vessel disease, total homocysteine has also been related to small vessel disease in other vascular beds, including in chronic kidney disease and diabetic retinopathy. ${ }^{51,52}$ In fact, some studies have indicated that total homocysteine-lowering therapy with vitamin B may slow the progression of white matter lesions of brain. ${ }^{53,54}$ Given all of the aforementioned data, we think that total homocysteine-lowering therapy might provide more benefit on small vessel disease than large vessel atherosclerosis, and would provide a larger protective effect on overall stroke versus myocardial infarction.

Folic acid food fortification program was introduced in United States and Canada since 1998 for prevention of neural tube defect in newborn. ${ }^{55}$ The US program added $140 \mu \mathrm{g}$ of folic acid per $100 \mathrm{~g}$ of enriched cereal grain product and has been estimated to provide 100 to $200 \mu \mathrm{g}$ of folic acid per day to women of childbearing age..$^{55}$ Study found the mean folate concentrations increased from 4.6 to $10.0 \mathrm{ng} / \mathrm{mL}$ and the mean total homocysteine concentration decreased from 10.1 to 9.4 $\mu \mathrm{mol} / \mathrm{L}$ after folic acid fortification. ${ }^{56}$ Moreover, the prevalence of low folate concentrations $(<3 \mathrm{ng} / \mathrm{mL})$ decreased from $22 \%$ to $1.7 \%$ and the prevalence of high total homocysteine concentrations ( $>13 \mu \mathrm{mol} / \mathrm{L}$ ) decreased from 18.7\% to $9.8 \%$ after folic acid fortification. ${ }^{56}$ Epidemiology study found the stroke mortality improved in United States and Canada after folic acid fortification. ${ }^{9}$ A dose-finding trial found folic acid dose as low as $0.2 \mathrm{mg} /$ day, if given for more than 6 months, effectively lowered total homocysteine concentration by $8 \%$ to $20 \%$ as higher dose ( 0.4 and $0.8 \mathrm{mg} /$ day). ${ }^{57}$ The study also found folic acid $0.8 \mathrm{mg} /$ day achieved maximal total homocysteine-lowering response by 6 weeks but then the total homocysteine level remained stationary by 6 months. ${ }^{57}$ Therefore additional folic acid supplementation in the countries with folic acid food fortification may not reduce stroke risk further. A case-control study found in the era of folic acid fortification, vitamin B6 had stronger association with stroke than total homocysteine. ${ }^{58}$ Therefore, in the countries with folic acid fortification, other risk factors other than total homocysteine may be more important for the prevention of stroke.

Although this meta-analysis included only RCTs, there were some limitations. First, meta-analysis is retrospective research that can be constrained by the comprehensiveness of searches, methodological rigor of the included studies, and publication bias. We tried to maximize study identification and minimize bias by developing the study protocol a priori, performing a thorough search of several databases, and using explicit criteria for study selection, data collection, and data analysis. Second, inevitable bias lies in the different characteristics of study par- ticipants, treatment duration and intensity, type of cerebrovascular events identified, baseline folate and total homocysteine concentration, percentage of concomitant antiplatelet or statin use and other study design variables. Third, since only two trials reported an endpoint of ischemic stroke and one trial reported an endpoint of hemorrhagic stroke, insufficient evidence can be obtained on these endpoints.

\section{Conclusions}

In conclusion, our meta-analysis demonstrated a significant benefit of folic acid supplement in preventing stroke in countries without mandatory folic acid food fortification. The benefit was found mostly in patients receiving folic acid alone or combination of folic acid and minimal cyanocobalamin $(\leq 0.05 \mathrm{mg} /$ day) but not found in trials with combination of folic acid and cyanocobalamin ( $\geq 0.4 \mathrm{mg} /$ day). Since the number of patients evaluated stroke of current RCTs almost reached the required information sizes and the summarized observed effect has crossed benefit boundary, no more relevant RCTs are needed to be conducted in countries without mandatory folic acid fortification. Because folic acid supplementation is an inexpensive, safe, and widely applicable intervention, a nutritional supplementation of folic acid by food or medication should be promoted in countries where food was not fortified with folic acid.

\section{Supplementary materials}

Supplementary materials related to this article can be found online at https://doi.org/10.5853/jos.2017.01522.

\section{Disclosure}

The authors have no financial conflicts of interest.

\section{References}

1. Homocysteine Studies Collaboration. Homocysteine and risk of ischemic heart disease and stroke: a meta-analysis. JAMA 2002;288:2015-2022.

2. Stanger $\mathrm{O}$, Herrmann W, Pietrzik K, Fowler B, Geisel J, Dierkes $J$, et al. Clinical use and rational management of homocysteine, folic acid, and B vitamins in cardiovascular and thrombotic diseases. Z Kardiol 2004;93:439-453.

3. Homocysteine Lowering Trialists' Collaboration. Dose-dependent effects of folic acid on blood concentrations of homocysteine: a meta-analysis of the randomized trials. Am J Clin Nutr 2005;82:806-812. 
4. Martí-Carvajal AJ, Solà I, Lathyris D. Homocysteine-lowering interventions for preventing cardiovascular events. Cochrane Database Syst Rev 2015;1:CD006612.

5. Li Y, Huang T, Zheng Y, Muka T, Troup J, Hu FB. Folic acid supplementation and the risk of cardiovascular diseases: a meta-analysis of randomized controlled trials. J Am Heart Assoc 2016;5:e003768.

6. Lee M, Hong KS, Chang SC, Saver JL. Efficacy of homocysteine-lowering therapy with folic acid in stroke prevention: a meta-analysis. Stroke 2010;41:1205-1212.

7. Huo Y, Qin X, Wang J, Sun N, Zeng Q, Xu X, et al. Efficacy of folic acid supplementation in stroke prevention: new insight from a meta-analysis. Int J Clin Pract 2012;66:544-551.

8. Ji Y, Tan S, Xu Y, Chandra A, Shi C, Song B, et al. Vitamin B supplementation, homocysteine levels, and the risk of cerebrovascular disease: a meta-analysis. Neurology2013;81:1298-1307.

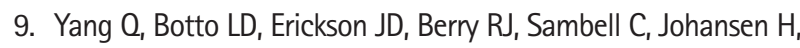
et al. Improvement in stroke mortality in Canada and the United States, 1990 to 2002. Circulation 2006;113:1335-1343.

10. Huo $Y$, Li J, Qin X, Huang Y, Wang $X$, Gottesman RF, et al. Efficacy of folic acid therapy in primary prevention of stroke among adults with hypertension in China: the CSPPT randomized clinical trial. JAMA 2015;313:1325-1335.

11. Kotwal J, Kotwal A, Bhalla S, Singh PK, Nair V. Effectiveness of homocysteine lowering vitamins in prevention of thrombotic tendency at high altitude area: a randomized field trial. Thromb Res 2015;136:758-762.

12. Moher D, Liberati A, Tetzlaff J, Altman DG; PRISMA Group. Preferred reporting items for systematic reviews and metaanalyses: the PRISMA statement. BMJ 2009;339:b2535.

13. Higgins J, Green S. Cochrane Handbook for Systematic Reviews of Interventions. Oxford, UK: The Cochrane Collaboration, 2008.

14. Sterne JA, Egger M. Funnel plots for detecting bias in metaanalysis: guidelines on choice of axis. J Clin Epidemiol 2001; 54:1046-1055.

15. Wetterslev J, Thorlund K, Brok J, Gluud C. Trial sequential analysis may establish when firm evidence is reached in cumulative meta-analysis. J Clin Epidemiol 2008;61:64-75.

16. Toole JF, Malinow MR, Chambless LE, Spence JD, Pettigrew LC, Howard VJ, et al. Lowering homocysteine in patients with ischemic stroke to prevent recurrent stroke, myocardial infarction, and death: the Vitamin Intervention for Stroke Prevention (visp) randomized controlled trial. JAMA 2004;291:565-575.

17. Wrone EM, Hornberger JM, Zehnder JL, McCann LM, Coplon NS, Fortmann SP. Randomized trial of folic acid for prevention of cardiovascular events in end-stage renal disease. $J$ Am Soc Nephrol 2004;15:420-426.
18. Lonn E, Yusuf S, Arnold MJ, Sheridan P, Pogue J, Micks M, et al. Homocysteine lowering with folic acid and $B$ vitamins in vascular disease. N Engl J Med 2006;354:1567-1577.

19. Cole BF, Baron JA, Sandler RS, Haile RW, Ahnen DJ, Bresalier $\mathrm{RS}$, et al. Folic acid for the prevention of colorectal adenomas: a randomized clinical trial. JAMA 2007;297:2351-2359.

20. Jamison RL, Hartigan P, Kaufman JS, Goldfarb DS, Warren SR, Guarino PD, et al. Effect of homocysteine lowering on mortality and vascular disease in advanced chronic kidney disease and end-stage renal disease: a randomized controlled trial. JAMA 2007;298:1163-1170.

21. Albert CM, Cook NR, Gaziano JM, Zaharris E, MacFadyen J, Danielson $E$, et al. Effect of folic acid and $B$ vitamins on risk of cardiovascular events and total mortality among women at high risk for cardiovascular disease: a randomized trial. JAMA 2008;299:2027-2036.

22. House $A A$, Eliasziw $M$, Cattran $D C$, Churchill DN, Oliver MJ, Fine $A$, et al. Effect of $B$-vitamin therapy on progression of diabetic nephropathy: a randomized controlled trial. JAMA 2010;303:1603-1609.

23. Bostom AG, Carpenter MA, Kusek JW, Levey AS, Hunsicker $L$, Pfeffer MA, et al. Homocysteine-lowering and cardiovascular disease outcomes in kidney transplant recipients: primary results from the folic acid for vascular outcome reduction in transplantation trial. Circulation 2011;123:1763-1770.

24. Lamas GA, Boineau R, Goertz C, Mark DB, Rosenberg Y, Stylianou $M$, et al. Oral high-dose multivitamins and minerals after myocardial infarction: a randomized trial. Ann Intern Med 2013;159:797-805.

25. Mark SD, Wang W, Fraumeni JF Jr, Li JY, Taylor PR, Wang GQ, et al. Lowered risks of hypertension and cerebrovascular disease after vitamin/mineral supplementation: the Linxian Nutrition Intervention Trial. Am J Epidemiol 1996;143:658-664.

26. Liem $A H$, van Boven $A J$, Veeger NJ, Withagen $A J$, Robles de Medina RM, Tijssen JG, et al. Efficacy of folic acid when added to statin therapy in patients with hypercholesterolemia following acute myocardial infarction: a randomised pilot trial. Int J Cardiol 2004;93:175-179.

27. Liem A, Reynierse-Buitenwerf GH, Zwinderman AH, Jukema JW, van Veldhuisen DJ. Secondary prevention with folic acid: results of the Goes extension study. Heart 2005;91:1213-1214.

28. Bønaa KH, Njølstad I, Ueland PM, Schirmer H, Tverdal A, Steigen $T$, et al. Homocysteine lowering and cardiovascular events after acute myocardial infarction. N Engl J Med 2006;354:1578-1588.

29. Righetti M, Serbelloni P, Milani S, Ferrario G. Homocysteinelowering vitamin $B$ treatment decreases cardiovascular events in hemodialysis patients. Blood Purif 2006;24:379-386. 
30. Zoungas S, McGrath BP, Branley P, Kerr PG, Muske C, Wolfe $\mathrm{R}$, et al. Cardiovascular morbidity and mortality in the Atherosclerosis and Folic Acid Supplementation Trial (asfast) in chronic renal failure: a multicenter, randomized, controlled trial. J Am Coll Cardiol 2006;47:1108-1116.

31. Ebbing $M$, Bleie $\emptyset$, Ueland PM, Nordrehaug JE, Nilsen DW, Vollset SE, et al. Mortality and cardiovascular events in patients treated with homocysteine-lowering $B$ vitamins after coronary angiography: a randomized controlled trial. JAMA 2008;300:795-804.

32. Galan P, Kesse-Guyot E, Czernichow S, Briancon S, Blacher J, Hercberg $S$, et al. Effects of B vitamins and omega 3 fatty acids on cardiovascular diseases: a randomised placebo controlled trial. BMJ 2010;341:c6273.

33. VITATOPS Trial Study Group. B vitamins in patients with recent transient ischaemic attack or stroke in the vitamins to Prevent Stroke (vitatops) trial: a randomised, double-blind, parallel, placebo-controlled trial. Lancet Neurol 2010;9:855-865.

34. Heinz J, Kropf S, Domröse U, Westphal S, Borucki K, Luley C, et al. $B$ vitamins and the risk of total mortality and cardiovascular disease in end-stage renal disease: results of a randomized controlled trial. Circulation 2010;121:1432-1438.

35. Study of the Effectiveness of Additional Reductions in Cholesterol and Homocysteine (SEARCH) Collaborative Group, Armitage JM, Bowman L, Clarke RJ, Wallendszus K, Bulbulia $R$, et al. Effects of homocysteine-lowering with folic acid plus vitamin B12 vs placebo on mortality and major morbidity in myocardial infarction survivors: a randomized trial. JAMA 2010;303:2486-2494.

36. Spence JD, House AA, Eliasziw M. B-vitamin therapy for diabetic nephropathy: reply. JAMA 2010;304:636-637.

37. Spence JD, Bang $H$, Chambless LE, Stampfer MJ. Vitamin intervention for stroke prevention trial: an efficacy analysis. Stroke 2005;36:2404-2409.

38. Spence JD, Yi Q, Hankey GJ. B vitamins in stroke prevention: time to reconsider. Lancet Neurol 2017;16:750-760.

39. Spence JD, Stampfer MJ. Understanding the complexity of homocysteine lowering with vitamins: the potential role of subgroup analyses. JAMA 2011;306:2610-2611.

40. Xu X, Qin X, Li Y, Sun D, Wang J, Liang M, et al. Efficacy of folic acid therapy on the progression of chronic kidney disease: the renal substudy of the China stroke primary prevention trial. JAMA Intern Med 2016;176:1443-1450.

41. Robertson J, lemolo F, Stabler SP, Allen RH, Spence JD. Vitamin B12, homocysteine and carotid plaque in the era of folic acid fortification of enriched cereal grain products. CMAJ 2005;172:1569-1573.

42. Spence JD. Metabolic vitamin B12 deficiency: a missed oppor- tunity to prevent dementia and stroke. Nutr Res 2016;36:109116.

43. Iso H, Moriyama $Y$, Sato $S$, Kitamura A, Tanigawa $T$, Yamagishi $K_{1}$ et al. Serum total homocysteine concentrations and risk of stroke and its subtypes in Japanese. Circulation 2004;109:2766-2772.

44. Perini F, Galloni E, Bolgan I, Bader G, Ruffini R, Arzenton E, et al. Elevated plasma homocysteine in acute stroke was not associated with severity and outcome: stronger association with small artery disease. Neurol Sci 2005;26:310-318.

45. Khan U, Crossley C, Kalra L, Rudd A, Wolfe CD, Collinson P, et al. Homocysteine and its relationship to stroke subtypes in a uk black population: the south London ethnicity and stroke study. Stroke 2008;39:2943-2949.

46. Ma Y, Zhao X, Zhang W, Liu L, Wang Y, Fang R, et al. Homocysteine and ischemic stroke subtype: a relationship study in Chinese patients. Neurol Res 2010;32:636-641.

47. Vermeer SE, van Dijk EJ, Koudstaal PJ, Oudkerk M, Hofman A, Clarke $\mathrm{R}$, et al. Homocysteine, silent brain infarcts, and white matter lesions: the Rotterdam Scan Study. Ann Neurol 2002;51:285-289.

48. Seshadri S, Wolf PA, Beiser AS, Selhub J, Au R, Jacques PF, et al. Association of plasma total homocysteine levels with subclinical brain injury: cerebral volumes, white matter hyperintensity, and silent brain infarcts at volumetric magnetic resonance imaging in the Framingham Offspring Study. Arch Neurol 2008;65:642-649.

49. Tseng YL, Chang YY, Liu JS, Su CS, Lai SL, Lan MY. Association of plasma homocysteine concentration with cerebral white matter hyperintensity on magnetic resonance images in stroke patients. J Neurol Sci 2009;284:36-39.

50. Kloppenborg RP, Nederkoorn PJ, van der Graaf Y, Geerlings MI. Homocysteine and cerebral small vessel disease in patients with symptomatic atherosclerotic disease. The SMARTMR study. Atherosclerosis 2011;216:461-466.

51. Xu C, Wu Y, Liu G, Liu X, Wang F, Yu J. Relationship between homocysteine level and diabetic retinopathy: a systematic review and meta-analysis. Diagn Pathol 2014;9:167.

52. Xie D, Yuan Y, Guo J, Yang S, Xu X, Wang Q, et al. Hyperhomocysteinemia predicts renal function decline: a prospective study in hypertensive adults. Sci Rep 2015;5:16268.

53. Cavalieri M, Schmidt R, Chen $C$, Mok V, de Freitas GR, Song $S$, et al. B vitamins and magnetic resonance imaging-detected ischemic brain lesions in patients with recent transient ischemic attack or stroke: the vitamins to Prevent Stroke (VITATOPS) MRI-substudy. Stroke 2012;43:3266-3270.

54. Vermeulen EG, Stehouwer CD, Valk J, van der Knaap M, van den Berg $M$, Twisk JW, et al. Effect of homocysteine-lowering 
treatment with folic acid plus vitamin B on cerebrovascular atherosclerosis and white matter abnormalities as determined by MRA and MRI: a placebo-controlled, randomized trial. Eur J Clin Invest 2004;34:256-261.

55. Crider KS, Bailey LB, Berry RJ. Folic acid food fortification-its history, effect, concerns, and future directions. Nutrients 2011;3:370-384.

56. Jacques PF, Selhub J, Bostom AG, Wilson PW, Rosenberg IH. The effect of folic acid fortification on plasma folate and total homocysteine concentrations. N Engl J Med 1999;340:1449-
1454.

57. Tighe $P$, Ward M, McNulty H, Finnegan O, Dunne A, Strain J, et al. A dose-finding trial of the effect of long-term folic acid intervention: implications for food fortification policy. Am J Clin Nutr 2011;93:11-18.

58. Kelly PJ, Shih VE, Kistler JP, Barron M, Lee H, Mandell R, et al. Low vitamin B6 but not homocyst(e)ine is associated with increased risk of stroke and transient ischemic attack in the era of folic acid grain fortification. Stroke 2003;34:e51-e54. 


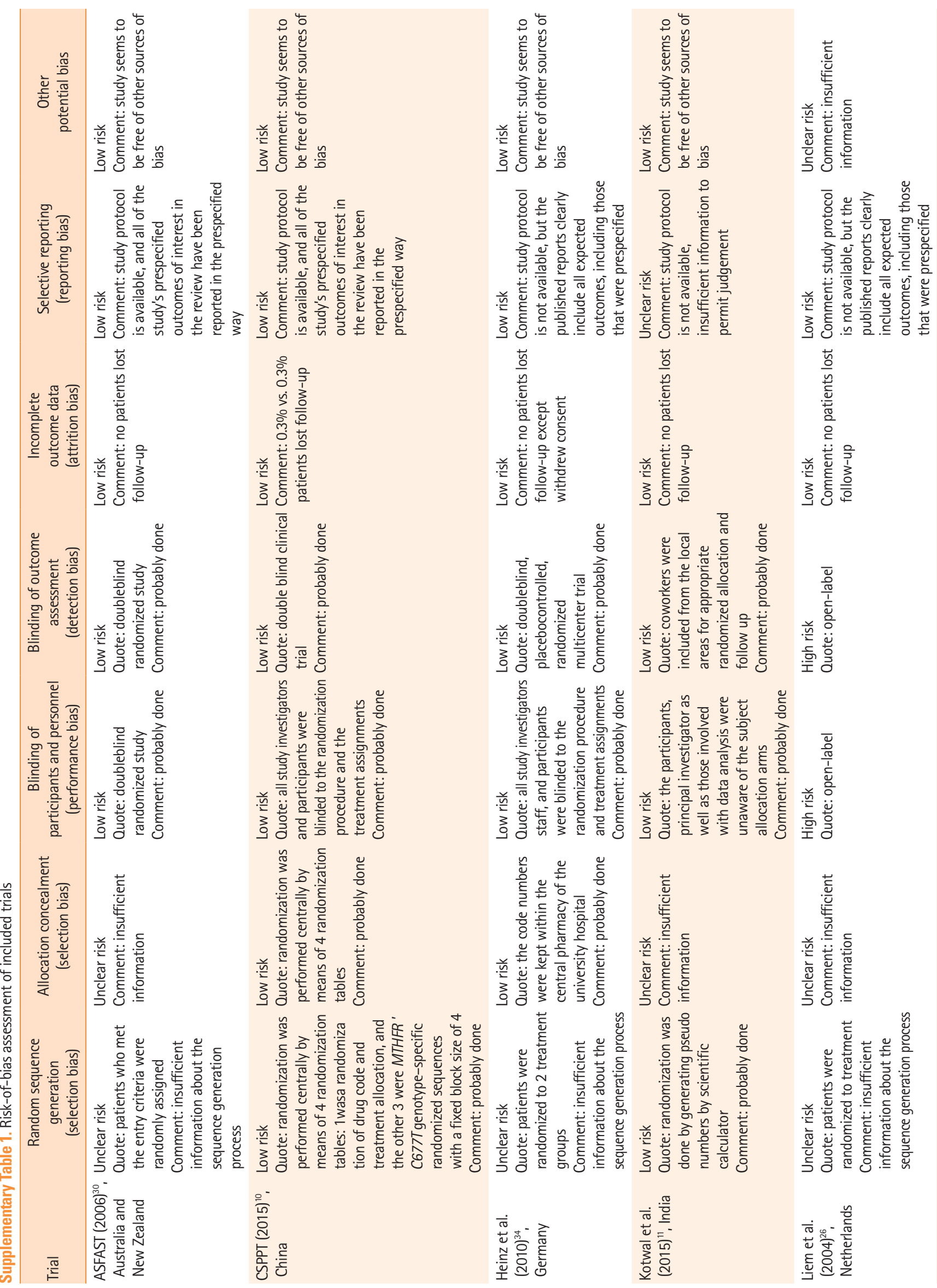




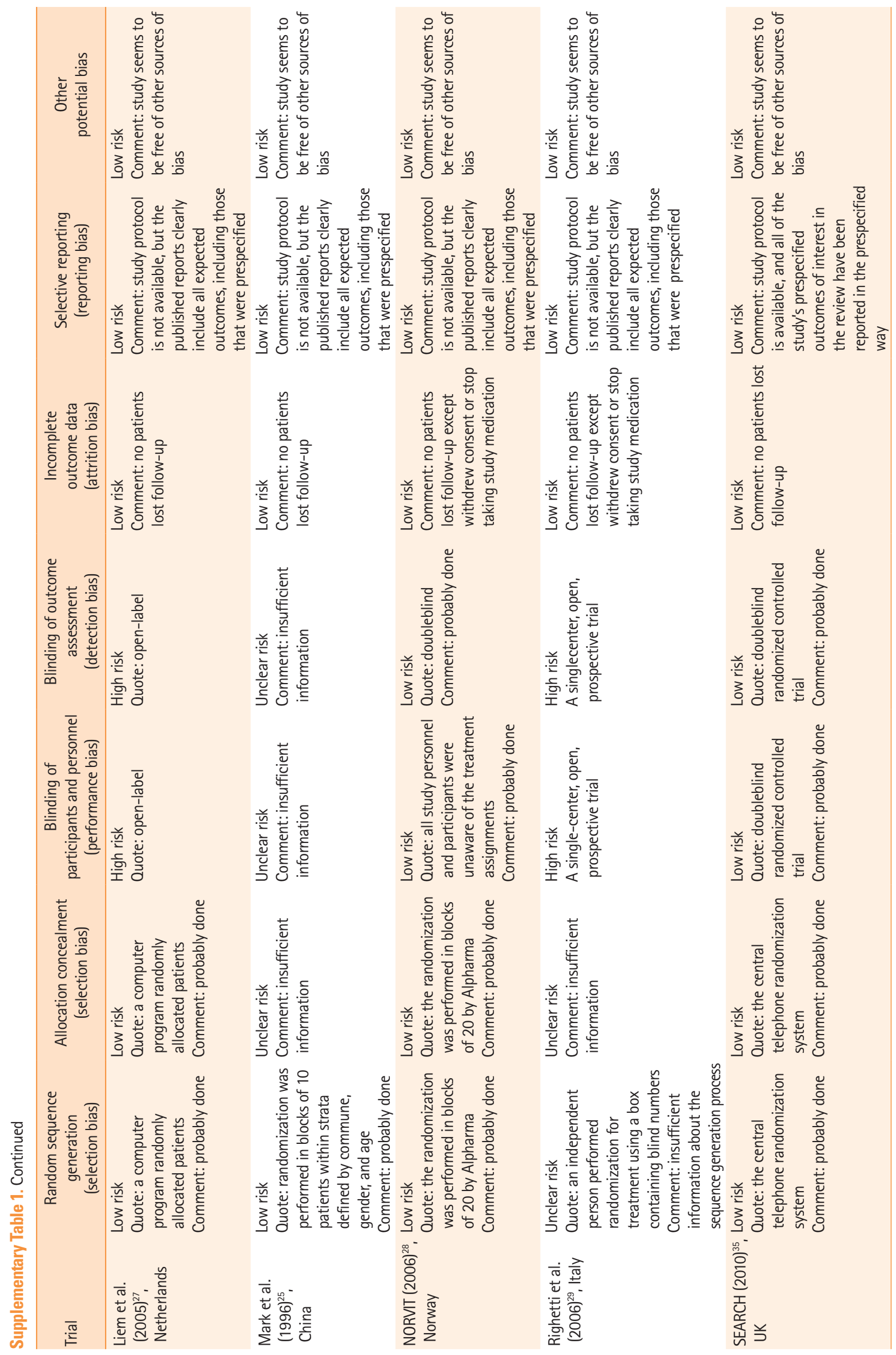




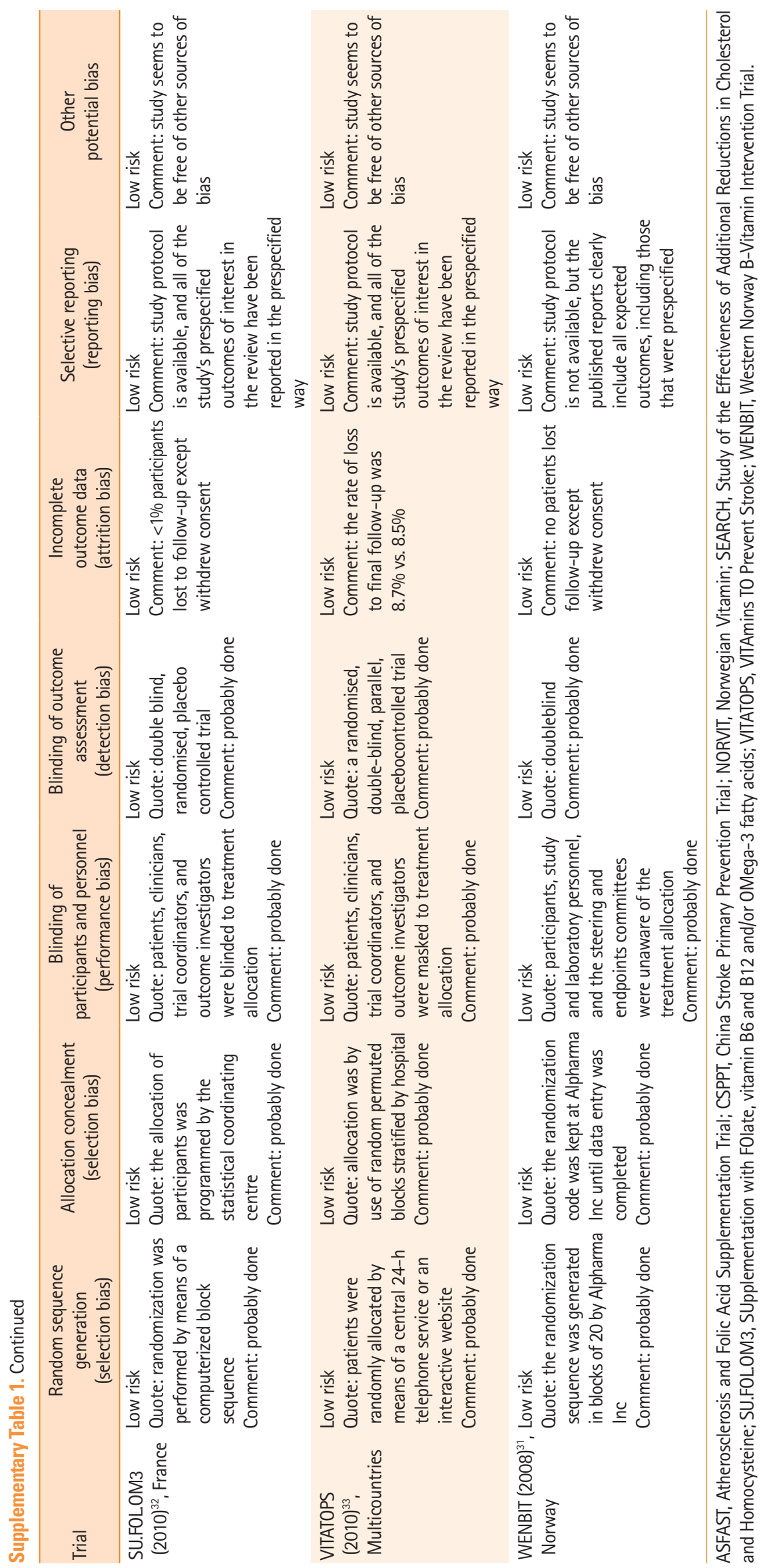




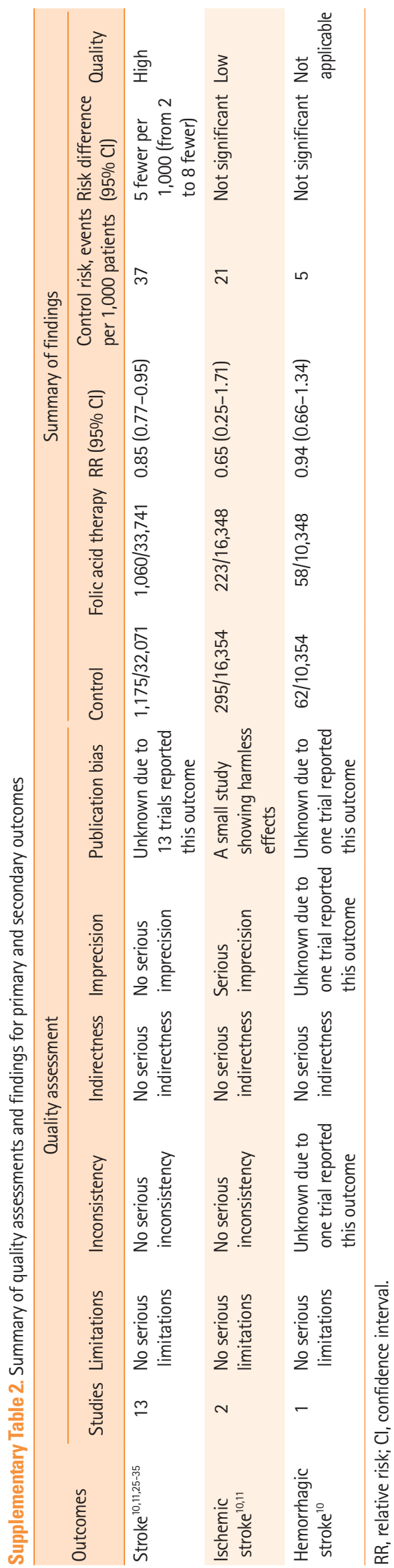




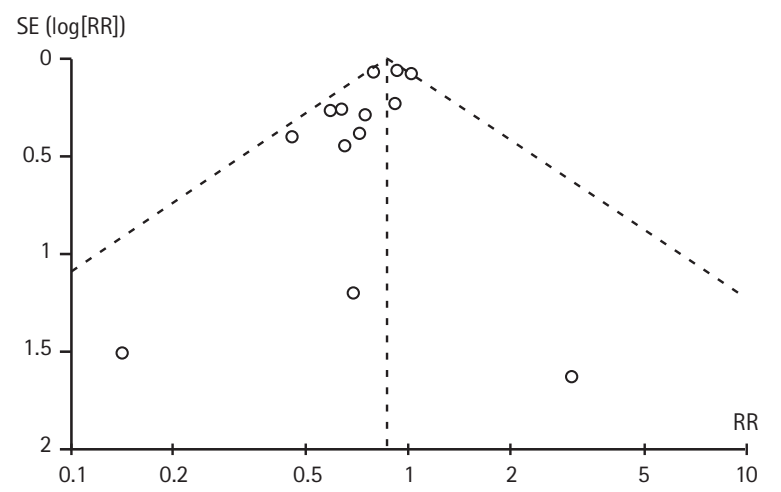

Supplementary Figure 1. Funnel plot. SE, standard error; RR, relative risk. 